\title{
EFFICACY OF LOW-DOSE THROMBOLYSIS WITH INTRAVENOUS ALTEPLASE WITHIN 6 H OF ACUTE ISCHEMIC STROKE ONSET: EVIDENCE FROM SINGLE REFERRAL CENTER IN INDONESIA
}

\section{AL RASYID ${ }^{1 *}$, SALIM HARRIS ${ }^{1}$, MOHAMMAD KURNIAWAN ${ }^{1}$, TAUFIK MESIANO ${ }^{1}$, RAKHMAD HIDAYAT ${ }^{1}$, HERQUTANTO², MEITY ASYARI RAHMADHANI ${ }^{1}$}

1Department of Neurology, Faculty of Medicine, University of Indonesia/Cipto Mangunkusumo Hospital, Jakarta 10430, Indonesia, ${ }^{2}$ Department of Community Medicine, Faculty of Medicine, University of Indonesia, Jakarta 10430, Indonesia

Email: alrasyid50@yahoo.com

Received: 10 May 2019 Revised and Accepted: 15 Jul 2019

ABSTRACT

Objective: This study evaluated the efficacy of thrombolysis with $0.6 \mathrm{mg} / \mathrm{kg}$ intravenous alteplase for acute ischemic stroke patients within $6 \mathrm{~h}$ of stroke onset.

Methods: This cross-sectional study collected data of patients with ischemic stroke received intravenous thrombolytic therapy with 0.6 mg/kg alteplase within $6 \mathrm{~h}$ of onset in Cipto Mangunkusumo General Hospital (Rumah Sakit Cipto Mangunkusumo [RSCM]) between November 2014 and August 2017. Efficacy of the thrombolytic therapy was evaluated using the National Institutes of Health Stroke Scale (NIHSS) and modified Rankin Scale (mRS). NIHSS evaluated on $24 \mathrm{~h}$ and $7 \mathrm{~d}$ post thrombolytic therapy portrayed clinical outcomes of patients while mRS evaluated on day 30 post-thrombolysis portrayed the functional outcome of patients.

Results: The median NIHSS score decreased on $24 \mathrm{~h}$ and $7 \mathrm{~d}$ post-thrombolysis. $33.3 \%$ patients experienced a reduction of NIHSS score $\geq 4$ on $24 \mathrm{~h}$ post thrombolytic therapy. On day 7 following thrombolysis, $57.4 \%$ patients had a good clinical outcome. On day 30 follow-up, $55.6 \%$ patients had a good functional outcome.

Conclusion: Thrombolysis using $0.6 \mathrm{mg} / \mathrm{kg}$ intravenous alteplase within $6 \mathrm{~h}$ of onset is effective for acute ischemic stroke patients

Keywords: Efficacy, Thrombolysis, Alteplase, Ischemic stroke, Indonesia

(C) 2019 The Authors. Published by Innovare Academic Sciences Pvt Ltd. This is an open access article under the CC BY license (http://creativecommons.org/licenses/by/4.0/] DOI: http://dx.doi.org/10.22159/ijpps.2019v11i8.34029

\section{INTRODUCTION}

Stroke is a serious problem in Asia with mortality rate higher than in Europe or North America [1]. Two-third of total mortality caused by stroke in the world happened in Asia [2]. Stroke can also cause permanent or long-term disability $[3,4]$. Ischemic stroke is the most common type of stroke in the world with a prevalence of $87 \%$ [5]. In Indonesia, stroke causes the highest mortality from non-communicable disease group with ischemia as the main etiology. Prevalence of stroke in Indonesia increased from $8.3 / 1000$ population in 2007 to $12.1 / 1000$ population in 2013 [6]. In 2018, the prevalence of stroke decreased to $10.9 / 1000$ population [7]. Prevalence of stroke increased with age [6, 7]. Stroke is the leading etiology of death and disability [4].

Ischemic stroke is caused either by an embolus, thrombus, or systemic hypoperfusion. These conditions cause sudden loss of blood circulation to the brain, spinal cord, or retina. In the brain, ischemia will create irreversible death core zone surrounded by hypoperfusion zone called penumbra, which still can be saved [8]. Penumbra can be salvaged with reperfusion therapy. Reperfusion therapy can return blood circulation to the ischemic penumbra either by injection of thrombolytic drugs or removal of the thrombus via thrombectomy.

National Institute of Neurological Disorders and Stroke (NINDS) organized recombinant tissue plasminogen activator (r-TPA) stroke study in 1995 which demonstrated that intravenous alteplase therapy within $3 \mathrm{~h}$ of stroke onset improved functional outcome. Since then, this treatment has been approved as recommended first-line therapy for patients with acute ischemic stroke by most national and international guidelines. In Japan Alteplase Clinical Trial (J-ACT) conducted from April 2002 to September 2003, low-dose alteplase 0.6 $\mathrm{mg} / \mathrm{kg}$ was selected based on previous r-TPA studies for Japanese patients which suggested that 20 MIU of duteplase-r-TPA similar to alteplase, was non-inferior than 30 MIU towards partial recanalization and complete recanalization. Therefore, $0.6 \mathrm{mg} / \mathrm{kg}$ of alteplase-which was equivalent to $20 \mathrm{MIU}$ per person or $0.33 \mathrm{MIU} / \mathrm{kg}$ at a mean body weight $60 \mathrm{~kg}$, was considered as the optimal dose for J-ACT [9]. Enhanced Control of Hypertension and Thrombolysis Stroke Study (ENCHANTED) involving predominantly Asian patients with acute ischemic stroke also showed that the low-dose alteplase was noninferior to the standard dose $(0.9 \mathrm{mg} / \mathrm{kg})[10]$.

Despite stroke having high prevalence in the world, especially in Asia, the popularity of thrombolytic therapy in developing countries is still low. Thrombolytic therapy rate in Indonesia is not available yet. In Indonesia, most thrombolytic therapies were done in Cipto Mangunkusumo General Hospital (Rumah Sakit Cipto Mangunkusumo [RSCM]) as the referral center. Therefore, this study indirectly can represent the situation of thrombolytic therapy in Indonesia. Cipto Mangunkusumo General Hospital has performed thrombolytic therapy since 2014 using $0.6 \mathrm{mg} / \mathrm{kg}$ alteplase with onset-to-therapy time up to 6 $\mathrm{h}$. The purpose of these regulations is to gain the best benefits of thrombolytic therapy with minimum therapeutically effective dose required and longest onset-to-therapy time allowed.

Outcome of the thrombolytic therapy on stroke patients can be evaluated using the National Institutes of Health Stroke Scale (NIHSS) and modified Rankin Scale (mRS). NIHSS evaluates impairment of the patient while mRS evaluates disability of the patient. NIHSS can be used to measure severity of symptoms related with brain infarction and to evaluate post-stroke neurologic deficit. NIHSS score can range between 0-42. Higher score represents more severe impairment [11]. mRS measures patient's independency post-stroke. mRS score consists of 0 (no symptoms) to 6 (dead) [12].

The aim of this study was to investigate the efficacy of $0.6 \mathrm{mg} / \mathrm{kg}$ intravenous alteplase injected on acute ischemic stroke patients within $6 \mathrm{~h}$ of stroke onset using NIHSS and mRS evaluation. 


\section{MATERIALS AND METHODS}

\section{Subjects and procedures}

In this cross-sectional study, the patient's data were obtained from the medical records. The subjects in this study were adult acute ischemic stroke patients admitted to the Cipto Mangunkusumo General Hospital between November 2014 and August 2017 undergoing intravenous thrombolytic therapy with $0.6 \mathrm{mg} / \mathrm{kg}$ alteplase within $6 \mathrm{~h}$ of stroke onset. Diagnosis of ischemic stroke was confirmed by cerebral computed tomography examination. Patients with posterior circulation infarct (POCI) or underwent intra-arterial therapy (IAT) or mechanical thrombectomy were excluded from this study. Patients receiving a dose of alteplase other than $0.6 \mathrm{mg} / \mathrm{kg}$ or having thrombolytic therapy interrupted due to bleeding or allergic reaction were also excluded from this study. Factors could potentially influence the outcome of the therapy (e. g. dehydration, infection, etc.) had been evaluated and treated based on applied guidelines.

Demographic, clinical, and laboratory data of patients, including National Institutes of Health Stroke Scale (NIHSS) score prethrombolysis, NIHSS 24-hours post-thrombolysis score, and NIHSS 7 -days post-thrombolysis score, were collected from the medical records. On day 90 post-thrombolysis, the functional outcome of the patient was evaluated using modified Rankin Scale (mRS) at the time of the outpatient visit or by phone. NIHSS evaluation at $24 \mathrm{~h}$ and $7 \mathrm{~d}$ after thrombolytic therapy were indicators of the patient's clinical outcome. Clinical outcome and functional outcome were indicators of efficacy evaluation of thrombolytic therapy using $0.6 \mathrm{mg} / \mathrm{kg}$ alteplase within $6 \mathrm{~h}$ of stroke onset in this study.

Reduction of NIHSS score before thrombolysis as much as four or more on $24 \mathrm{~h}$ and/or $7 \mathrm{~d}$ after thrombolytic therapy was categorized as the good clinical outcome. Score $0-2$ of mRS on day 90 post- thrombolysis were categorized as the good functional outcome while score 3-6 were categorized as the poor functional outcome.

This study also evaluated the possibility of non-modifiable and modifiable cerebrovascular risk factors affecting the outcomes of the therapy. Non-modifiable risk factors consisted of age and sex while modifiable risk factors consisted of hypertension, diabetes mellitus, smoking, using antiplatelet and/or anticoagulant agents, atrial fibrillation, and previous stroke history.

\section{Statistical analysis}

Numerical data in this study were presented as means and standard deviation if normally distributed, and as median and range if not normally distributed. Categorical data were presented as frequencies and percentages. Statistical analysis was performed using SPSS version 20. Normality of numerical data was tested using the Kolmogorov-Smirnov normality test due to the number of subject $>50$. Independent t-test or Mann-Whitney U-test was used to compare means in numerical data while chi-square test or Fisher's exact test was used to compare percentages in categorical data.

\section{RESULTS}

There were 646 stroke patients treated in Cipto Mangunkusumo General Hospital between November 2014 and August 2017. Most stroke was ischemic stroke $(65 \% ; n=420) .73$ ischemic stroke patients $(17.4 \%)$ received thrombolytic therapy. Thrombolytic therapy on two patients was stopped due to hematemesis and allergic reaction. One patient received thrombolytic therapy more than $6 \mathrm{~h}$ of stroke onset. Eight patients were given a dose of alteplase other than $0.6 \mathrm{mg} / \mathrm{kg}$. Intravenous thrombolysis on two patients was continued with intra-arterial thrombolysis and on five patients was continued with thrombectomy. In total, there were 54 patients met the inclusion criteria of this study (fig. 1).

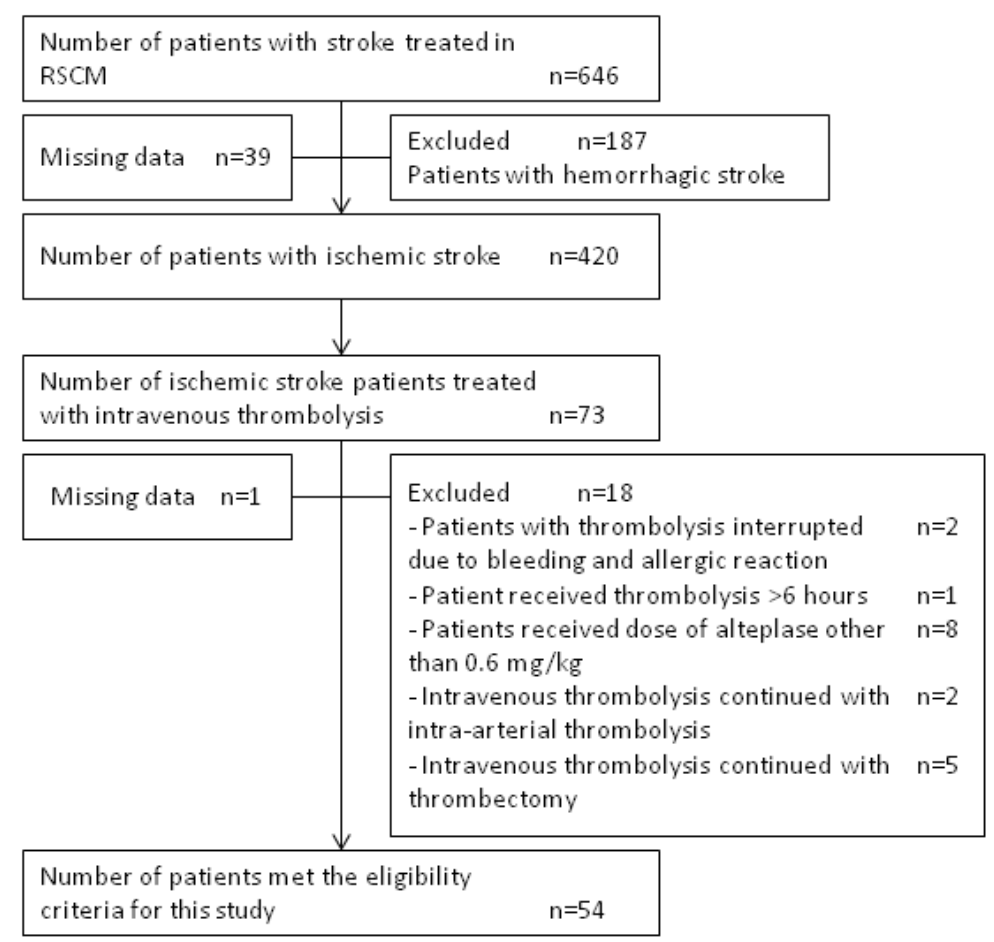

Fig. 1: Flow chart showing the selection of patients

Almost half of the patients (42.6\%) agec $60 \mathrm{y}$ old. The mean and standard deviation for age was $56 \pm 11.71 \mathrm{y}$ old. Of all patients, $51.9 \%$ were women, $22.2 \%$ had smoking history or were current smokers, $27.8 \%$ using antiplatelet agents just before the stroke, $3.7 \%$ using oral anticoagulant agents or anticoagulant injection just before the stroke, $68.5 \%$ were hypertensive, $31.5 \%$ had diabetes mellitus, $20.4 \%$ had atrial fibrillation showed on electrocardiography, $53.7 \%$ had heart disease (coronary artery disease [CAD] or chronic heart failure [CHF] or both), and 22.2\% had previous stroke history. Most patients (51.9\%) had involvement of the left hemisphere-which associated with aphasia and functional dependency. Only 9.3\% patients received thrombolytic therapy before $3 \mathrm{~h}$ of stroke onset while $90.7 \%$ patients received thrombolytic therapy between 3-6 $\mathrm{h}$ of stroke onset. Table 1 shows baseline characteristics in 54 patients. Percentage of modifiable risk factors in patients is showed in fig. 2. 
Table 1: Baseline demographic and clinical characteristics of patients

\begin{tabular}{|c|c|c|}
\hline Variable & $\mathbf{n}$ & $\%$ \\
\hline \multicolumn{3}{|l|}{ Age, $y$} \\
\hline$<60$ & 31 & 57.4 \\
\hline$\geq 60$ & 23 & 42.6 \\
\hline \multicolumn{3}{|l|}{ Sex } \\
\hline Male & 26 & 48.1 \\
\hline Female & 28 & 51.9 \\
\hline \multicolumn{3}{|c|}{ Previous stroke history } \\
\hline Yes & 12 & 22.2 \\
\hline \multirow{2}{*}{\multicolumn{3}{|c|}{ Using antiplatelet agents }} \\
\hline & & \\
\hline Yes & 15 & 27.8 \\
\hline No & 39 & 72.2 \\
\hline \multicolumn{3}{|c|}{ Using anticoagulant agents } \\
\hline Yes & 2 & 3.7 \\
\hline No & 52 & 96.3 \\
\hline \multicolumn{3}{|c|}{ Hemisphere lesion } \\
\hline Left & 28 & 51.9 \\
\hline Right & 26 & 48.1 \\
\hline \multicolumn{3}{|c|}{ Stroke subtype } \\
\hline TACI & 17 & 31.5 \\
\hline PACI & 26 & 48.1 \\
\hline LACI & 11 & 20.4 \\
\hline \multicolumn{3}{|c|}{ Onset-to-therapy time, $\mathrm{h}$} \\
\hline$<3$ & 5 & 9.3 \\
\hline $3-6$ & 49 & 90.7 \\
\hline
\end{tabular}

TACI: total anterior circulation infarct, PACI: partial anterior circulation infarct, LACI: lacunar infarct

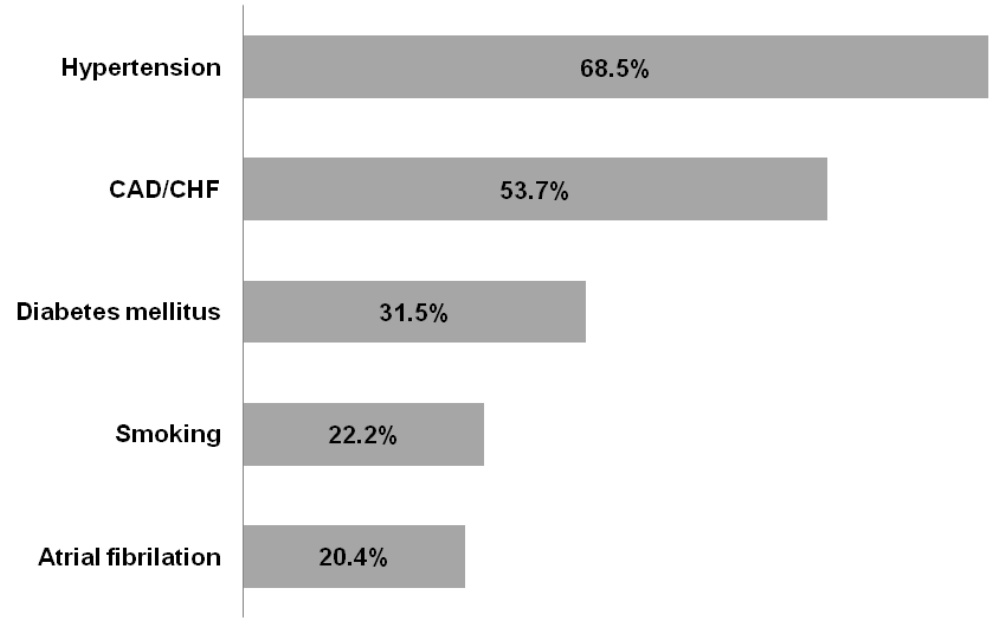

Fig. 2: Percentage of cerebrovascular modifiable risk factors in patients

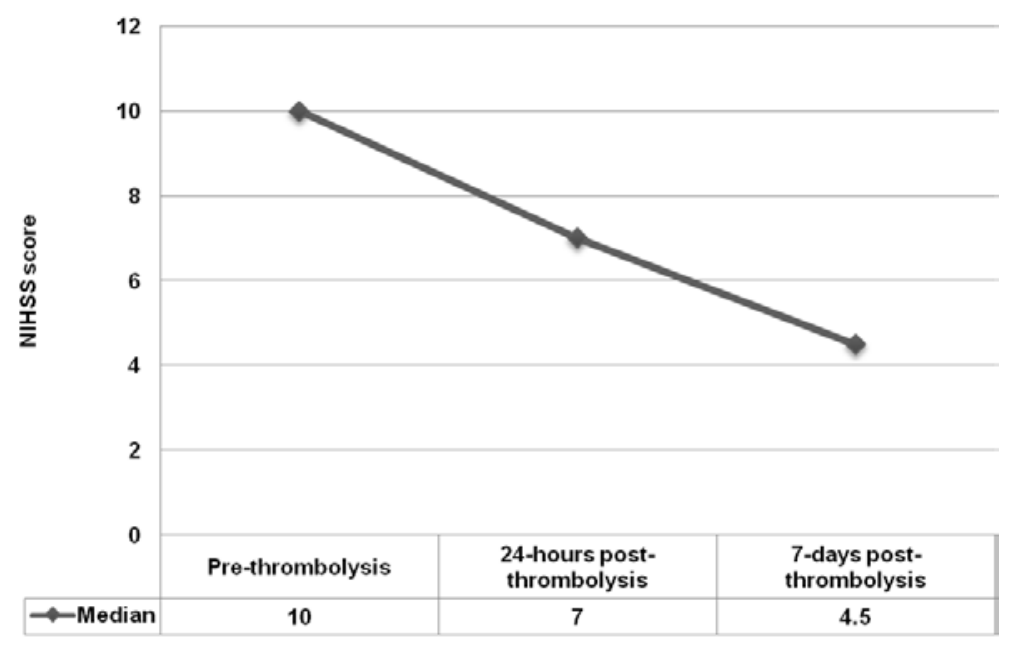

Fig. 3: Line chart showing a decrease of NIHSS median from pre-thrombolysis to $24 \mathrm{~h}$ and $7 \mathrm{~d}$ post-thrombolysis 


\section{Outcomes of patients}

Median National Institutes of Health Stroke Scale (NIHSS) score of patients before thrombolysis was 10 (range 4-16). The median decreased on $24 \mathrm{~h}$ and $7 \mathrm{~d}$ after thrombolytic therapy;
7 (range 2-42) and 4.5 (range 0-42), respectively (fig. 3). Reduction of NIHSS scores as much as four or more from the pre-thrombolysis score was experienced by $33.3 \%$ patients within $24 \mathrm{~h}$ and by $57.4 \%$ patients within $7 \mathrm{~d}$ following thrombolytic therapy (table 2 ).

Table 2: Clinical and functional outcomes of patients post thrombolytic therapy

\begin{tabular}{|c|c|c|}
\hline & $\mathbf{n}$ & $\%$ \\
\hline \multicolumn{3}{|c|}{ Clinical outcome } \\
\hline \multicolumn{3}{|c|}{ On 24 h post-thrombolysis } \\
\hline Good & 18 & 33.3 \\
\hline Poor & 36 & 66.7 \\
\hline \multicolumn{3}{|c|}{ On 7 d post-thrombolysis } \\
\hline Good & 31 & 57.4 \\
\hline Poor & 23 & 42.6 \\
\hline \multicolumn{3}{|c|}{$\begin{array}{l}\text { Functional outcome } \\
\text { mRS on day } 90\end{array}$} \\
\hline Good & 30 & 55.6 \\
\hline Poor & 24 & 44.4 \\
\hline
\end{tabular}

mRS: modified Rankin Scale.,

mRS score

$\because 0=1=2 \backsim 3=4 \backsim 5=6$

$\begin{array}{llllll}22.2 \% & 31.5 \% & 1.9 \% & 11.1 \% & 7.4 \% 1.9 \% & 21.4 \%\end{array}$

Fig. 4: Modified rankin scale (mRS) score at 3 mo

On the 90-days follow-up, 55.6\% patients had good functional outcome with modified Rankin Scale (mRS) scored 0-2. There were 31.5\% patients had mRS scored 1 and $22.2 \%$ patients had score 0 , as described in fig. 4. Pre-thrombolysis NIHSS score was categorized as $<10$ and $\geq 10$ based on its median. From statistical analysis performed, NIHSS score of patient before thrombolytic therapy affected clinical outcome on $24 \mathrm{~h}$ post-thrombolysis (odds ratio [OR] $=0.182 ; 95 \%$ confidence interval [CI]: 0.050-0.666; $\mathrm{p}=0.007)$. Pre-thrombolysis NIHSS score of patient also statistically affected the functional outcome on day 90 follow-up (OR=6.000; 95\% CI: 1.815-19.837; $p=0.002$ ).

\section{Correlation between risk factors and outcomes}

Smoking statistically affected the clinical outcome of patients on day 7 post-thrombolysis (OR=0.200; 95\% CI: 0.039-1.025; $\mathrm{p}=0.039$ ). Previous stroke history statistically affected the clinical outcome of patients on 24 h post thrombolytic therapy (OR=7.480; 95\% CI: 0.882 63.438; $\mathrm{p}=0.035$ ). Sex, age, antiplatelet and anticoagulant use, hypertension, diabetes mellitus, and atrial fibrillation did not influence the outcomes of the thrombolytic therapy statistically.

\section{DISCUSSION}

There was a balanced proportion between men and women in this study. The percentage of woman was $51.9 \%$, and the percentage of man was $49.1 \%$. These findings correspond with Riset Kesehatan Dasar (RISKESDAS) or basic health research in 2013. RISKESDAS 2013 stated that there was no imbalance prevalence of stroke between men and women in Indonesia [6]. The percentage of female patients in this study also resembled the result of the Third International Stroke Trial (IST-3) revealing that $52 \%$ of patients undergoing thrombolytic therapy were women [13]

Mean age of patients in this study was $55.6 \pm 11.7$ y old. $42.6 \%$ patients aged $\geq 60$ y old. These findings correspond with RISKESDAS stating that the highest prevalence of stroke was in the population aged $\geq 75 \mathrm{y}$ old and stroke prevalence increased with age $[6,7]$. The IST-3 was seeking efficacy of intravenous $0.9 \mathrm{mg} / \mathrm{kg}$ alteplase within $6 \mathrm{~h}$ of stroke onset in elderly patients. In IST-3 study, majority of the patients were older than 80 y old (53\%) [13].
Mean systolic blood pressure of patients on the first-time measurement was $150.43 \pm 29.96$ mmHg-similar with Japan Alteplase Clinical Trial (J-ACT) and National Institute of Neurological Disorders and Stroke (NINDS) 2 study; $151.0 \pm 19.0 \mathrm{mmHg}$ and $153 \pm 22 \mathrm{mmHg}$, respectively [9]. This result shows that blood pressure control-with routine consumption of antihypertensive drugs, in Indonesia had been decent.

Percentage of the antiplatelet user and the anticoagulant user in this study was $21.8 \%$ and $3.7 \%$, respectively. In Enhanced Control of Hypertension and Thrombolysis Stroke Study (ENCHANTED), the percentage of the antiplatelet user and the anticoagulant user of patients receiving $0.9 \mathrm{mg} / \mathrm{kg}$ alteplase was $21.1 \%$ and $2.1 \%$, respectively, and of patients receiving $0.6 \mathrm{mg} / \mathrm{kg}$ alteplase was $24.7 \%$ and $2.9 \%$, respectively. The percentage of the anticoagulant user in this study was slightly higher than ENCHANTED study most likely due to the higher percentage of the patient with atrial fibrillation in this study (53.7\%). In ENCHANTED study, percentage of patient with atrial fibrillation was $20.1 \%$ (patients receiving $0.9 \mathrm{mg} / \mathrm{kg}$ alteplase group) and $18.7 \%$ (patients receiving $0.6 \mathrm{mg} / \mathrm{kg}$ alteplase group) [10].

Mean blood glucose level of patients measured by stick test was $160.07 \pm 99.11 \mathrm{mg} / \mathrm{dl}(\sim 8.8 \mathrm{mmol} / \mathrm{l})$. The mean blood glucose level in this study was higher than J-ACT study $(141.3 \pm 48.3 \mathrm{mg} / \mathrm{dl})$ [9]. It was also higher than NINDS 2 study and Safe Implementation of Thrombolysis in Stroke-MOnitoring STudy (SITS-MOST) $[9,14]$. These findings show that blood glucose control in Indonesia was still lacking.

Most patients had left hemisphere lesion with partial anterior circulation infarct (PACI) as the most common subtype (48.1\%), followed by total anterior circulation infarct (TACI) $31.5 \%$ and lacunar infarct (LACI) 20.4\%. In IST-3, TACI was the most common subtype (42\%), followed by PACI (39\%) and LACI (11\%) [15]. There was a bigger involvement of larger blood vessel that associated with more severe stroke in IST-3 study than in this study.

Mean onset-to-therapy or onset-to-needle time of thrombolytic therapy in this study was $279.26 \pm 91.73 \mathrm{~min}(\sim 4 \mathrm{~h} 39 \mathrm{~min})$, and most patients $(53.7 \%)$ received thrombolytic therapy within $4.5-6 \mathrm{~h}$ since onset. In J-ACT study, the mean onset-to-therapy time was 
shorter than this study $(150.5 \pm 119.7 \mathrm{~min})$ because J-ACT set the onset-to-therapy time only up to $3 \mathrm{~h}$ [9]. IST-3 study set the onsetto-therapy time up to $4.5 \mathrm{~h}$; most patients received thrombolytic therapy within 3-4.5 $\mathrm{h} \mathrm{[14].}$

Modifiable risk factors of cerebrovascular disease having the highest percentage in this study were hypertension (68.5\%), heart disease (53.7\%), and diabetes mellitus (31.5\%). These results correspond with the result of the ENCHANTED study. In ENCHANTED study, hypertension had the highest percentage in both the low-dose alteplase group and the standard-dose alteplase group $(62.6 \%$ and $63.0 \%$, respectively). Chi-square test was performed to analyze the correlation between cerebrovascular risk factors and outcomes of thrombolytic therapy. Smoking was statistically proven affecting the clinical outcome of patients on day 7 post thrombolytic therapy (OR=0.200; $95 \% \mathrm{CI}$ : 0.039-1.025; $\mathrm{p}=0.039$ ). This result corresponds with ENCHANTED study revealing that smoking had the second-highest percentage as one of the modifiable risk factors in cerebrovascular diseases [10].

National Institutes of Health Stroke Scale (NIHSS) evaluation on $24 \mathrm{~h}$ post thrombolytic therapy was appointed as the primary outcome in NINDS and J-ACT study while modified Rankin Scale (mRS) evaluation on follow-up day 90 was the secondary outcome [9]. In this study, the functional outcome of patients was measured by mRS evaluated on day 90 post thrombolytic therapy, and clinical outcome was measured by NIHSS evaluated on $24 \mathrm{~h}$ and $7 \mathrm{~d}$ post-thrombolysis. NIHSS score reduction $\geq 4$ from the pre-thrombolysis NIHSS score was experienced by $33.3 \%$ patients within $24 \mathrm{~h}$ and by $57.4 \%$ patients within $7 \mathrm{~d}$ following the thrombolytic therapy. Percentage of patients experiencing $\geq 4$ NIHSS score reduction on $24 \mathrm{~h}$ post-thrombolysis in this study was lower than J-ACT study, which was $49.5 \%$. This gap is probably due to the different length of onset-to-therapy time set in JACT and this study. In J-ACT study, the onset-to-therapy time was only up to $3 \mathrm{~h}$. In this study, only $9.3 \%$ patients received thrombolytic therapy before $3 \mathrm{~h}$ of stroke onset while $90.7 \%$ patients received thrombolytic therapy between 3-6 h of onset. After three months, $55.6 \%$ patients had a good functional outcome with mRS scored $0-2$. According to Safe Implementation of Treatments in Stroke (SITS) Thrombolysis Registry, score $0-2$ on mRS day 90 post-thrombolysis portrayed functional independency-which happened on $55.4 \%$ subjects [16]. These findings show that longer onset-to-therapy time was associated with more variable clinical outcome. However, onsetto-therapy time did not affect the patient's functional independence. The length of onset-to-therapy time in ENCHANTED study was up to $4.5 \mathrm{~h}$. In ENCHANTED study, the thrombolytic therapy was considered delivering good outcome if the mRS scored 0 or 1 . mRS score 0 and 1 was owned by $25.1 \%$ and $21.7 \%$ patients in the low-dose group, respectively, and by $24.8 \%$ and $24.1 \%$ patients in the standard-dose group, respectively [10]. In this study, mRS score 0 was found in $22.2 \%$ patients and score 1 was found in $31.5 \%$ patients. This result shows that outcomes of thrombolytic therapy injected $\leq 6 \mathrm{~h}$ was noninferior to thrombolytic therapy injected $\leq 4.5 \mathrm{~h}$.

Based on statistical analysis performed in this study, NIHSS score pre-thrombolysis affected the clinical outcome on $24 \mathrm{~h}$ post thrombolytic therapy and the functional outcome measured on day 90 follow-up of the patient. These findings show that higher NIHSS score before thrombolytic therapy was correlated with more severe stroke-wider brain tissue damage and more extensive involvement of blood vessels, thus resulting in poorer outcomes of the patient.

This study used a cross-sectional method which only could represent a one-time condition. Confounding factors potentially influencing the outcome of the patients could not be controlled. This study also used a consecutive sampling method so that the samples were not normally distributed. Another limitation of this study was mRS on day 90 post-thrombolysis was collected through recall memory on some of the patients. However, the possibility of error was reduced with rechecking on the medical record data.

\section{CONCLUSION}

Results of this study suggest that thrombolysis with $0.6 \mathrm{mg} / \mathrm{kg}$ intravenous alteplase was non-inferior to those with $0.9 \mathrm{mg} / \mathrm{kg}$ intravenous alteplase used in Europe and North America. Thrombolytic therapy given within $6 \mathrm{~h}$ of onset was non-inferior to thrombolytic therapy injected $\leq 4.5 \mathrm{~h}$ although thrombolysis injected $\leq 3 \mathrm{~h}$ gave a more favorable outcome. In conclusion, thrombolysis with $0.6 \mathrm{mg} / \mathrm{kg}$ intravenous alteplase within $6 \mathrm{~h}$ of onset is effective for acute ischemic stroke patients.

\section{ACKNOWLEDGMENT}

The authors thank all the party involved in this study.

\section{AUTHORS CONTRIBUTIONS}

All the authors have contributed equally

\section{CONFLICT OF INTERESTS}

The authors declare that there is no conflict of interest

\section{REFERENCES}

1. Kim JS. Stroke in Asia: a global disaster. Int J Stroke 2014;9:856-7.

2. Mehndiratta MM, Khan M, Mehndiratta P, Wasay M. Stroke in Asia: geographical variations and temporal trends. J Neurol Neurosurg Psychiatry 2014;85:1308-12.

3. Rothwell PM, Coull AJ, Giles MF, Howard SC, Silver LE, Bull LM, et al. Change in stroke incidence, mortality, case-fatality, severity, and risk factors in oxfordshire, UK from 1981 to 2004 (Oxford Vascular Study). Lancet Lond Engl 2004;12:1925-33.

4. Mendis S, Weltgesundheitsorganisation, World Heart Federation editors. Global atlas on cardiovascular disease Prevention and control. Geneva: World Health Organization; 2011. p. 2-11.

5. Mozaffarian D, Go AS, Arnett DK, Blaha MJ, Cushman M, Das SR, et al. Heart disease and stroke statistics-2016 update: a report from the american heart association. Circulation 2016;26:e38-360.

6. Badan Penelitian dan Pengembangan Kesehatan, Riset kesehatan dasar riskesdas. Jakarta: Badan Penelitian dan Pengembangan Kesehatan; 2013.

7. Badan Penelitian dan Pengembangan Kesehatan. Hasil Riskesdas Jakarta: Badan Penelitian dan Pengembangan Kesehatan; 2018.

8. Caplan LR. Caplan's stroke: a clinical approach. Philadelphia: Elsevier/Saunders; 2009. p. 24.

9. Yamaguchi T, Mori E, Minematsu K, Nakagawara J, Hashi K, Saito I, et al. Alteplase at $0.6 \mathrm{mg} / \mathrm{kg}$ for acute ischemic stroke within $3 \mathrm{~h}$ of onset: Japan Alteplase Clinical Trial (J-ACT). Stroke 2006. p. 1810-5.

10. Anderson CS, Robinson T, Lindley RI, Arima H, Lavados PM, Lee $\mathrm{TH}$, et al. Low-dose versus standard-dose intravenous alteplase in acute ischemic stroke. N Engl J Med 2016;16:2313-23.

11. Lansberg MG, O’Donnell MJ, Khatri P, Lang ES, Nguyen Huynh MN, Schwartz NE, et al. Antithrombotic and thrombolytic therapy for ischemic stroke: antithrombotic therapy and prevention of thrombosis. $9^{\text {th }}$ ed: American College of Chest Physicians Evidence-Based Clinical Practice Guidelines. Chest; 2012. p. e601S-e636S.

12. Salter K, Jutai J, Zettler L, Moses M, McClure A, Mays R, et al. Outcome measures in stroke rehabilitation. Evidence-Based Review of Stroke Rehabilitation. London; 2005. p. 1-56.

13. IST-3 Collaborative Group, Sandercock P, Wardlaw JM, Lindley RI, Dennis M, Cohen G, et al. The benefits and harms of intravenous thrombolysis with recombinant tissue plasminogen activator within $6 \mathrm{~h}$ of acute ischaemic stroke (the third international stroke trial [IST-3]): a randomised controlled trial. Lancet Lond Engl 2012;23:2352-63.

14. Wahlgren N, Ahmed N, Davalos A, Hacke W, Millan M, Muir K, et al. Thrombolysis with alteplase 3-4.5 h after acute ischaemic stroke (SITS-ISTR): an observational study. Lancet Lond Engl 2008;11:1303-9.

15. Zinkstok S, Vermeulen M, Stam J, de Haan R, Roos Y. A randomised controlled trial of antiplatelet therapy in combination with Rt-PA thrombolysis in ischemic stroke: rationale and design of the ARTIStrial. Cerebrovasc Dis 2010;29:79-81.

16. SITS-Thrombolysis | SITS International. Available from: http://www.sitsinternational.org/registries/sits-thrombolysis/. [Last accessed on 13 Mar 2019]. 